JGG 2021;69:79-83

doi: 10.36150/2499-6564-464

\title{
COVID-19 older hospitalized patients: three clinical-psychological patterns
}

\author{
Silvia Poli ${ }^{1}$, Eugenia Cao di San Marco², Elisa Andrighi², \\ Elena A.M. Vegni ${ }^{1,2}$ \\ ${ }^{1}$ Department of Health Sciences, University of Milan, Italy; ${ }^{2}$ Unit of Clinical Psychology, San Paolo \\ University Hospital, Asst-Santi Paolo e Carlo, Milan, Italy
}

Background and aims. The COVID-19 outbreak is a far-reaching health crisis and a significant psychological stressor. COVID-19 patients experience an unknown and life-threatening condition that exposes them to strict social distancing, physical discomfort, medication side effects, long hospitalization, stigmatization and fear of death. Older people seem to be particularly vulnerable to the current pandemic from both a physical and a psychological point of view. The present article aims to describe different psychological reactions in older hospitalized COVID-19 patients encountered by the clinical psychology Unit of one of northern Italy most hit hospitals. Three prototypical clinical cases will be described and discussed. Insights about different attitudes towards the illness will be offered.

Conclusions. Auto-biographical narration among older hospitalized COVID-19 patients has positive effect. Hospital psychologist can support patients in the process of disease acceptance.

Received: May 14, 2020

Accepted: June 3, 2020

\section{Correspondence}

Silvia Poli

Department of Health Sciences, University of Milan, San Paolo University Hospital, via di Rudinì 8, 20142 Milan, Italy. Tel.: +3950323238

E-mail: silvia.poli@unimi.it

\section{Conflict of interest}

The Authors declare no conflict of interest

How to cite this article: Poli S, Cao di San Marco E, Andrighi E, et al. COVID-19 older hospitalized patients: three clinicalpsychological patterns.Journal of Gerontology and Geriatrics 2021;69:79-83. https://doi.org/10.36150/2499-6564-464

C Copyright by Società Italiana di Gerontologia e Geriatria (SIGG)

\section{(c) (1) () $\Theta$}

\section{OPEN ACCESS}

This is an open access article distributed in accordance with the CC-BY-NC-ND (Creative Commons Attribution-NonCommercial-NoDerivatives 4.0 International) license. The article can be used by giving appropriate credit and mentioning the license, but only for non-commercial purposes and only in the original version. For further information: https://creativecommons.org/licenses/by-nc-nd/4.0/deed.en
Key words: geriatrics, COVID-19, hospitalization, psychological reaction, health psychology

\section{INTRODUCTION}

The World Health Organization (WHO) declared the Coronavirus Disease 19 (COVID-19) outbreak a public health emergency of international concern on January $30^{\text {th }}, 2020$. Since March $11^{\text {th }}$, it has been declared a pandemic. Up to May $6^{\text {th }}, 3.672 .238$ confirmed cases have been reported, located in 215 countries. Italy is one of the most affected countries with 214.457 cases and 29.684 deaths ${ }^{1}$.

The COVID-19 pandemic is a significant psychological stressor for the general population as it is associated with uncertainty, fear of illness, social distancing, economic instability and drastic changes in everyday life ${ }^{2,3}$. COVID-19 patients have an even higher psychological burden as they experience strict social isolation, physical discomfort, medication side effects, long hospitalization, stigmatization, fear of virus transmission, and fear of death ${ }^{4}$.

A lot of the hospitalized patients are older adults as they are more easily infected and have an increased risk of developing severe diseases ${ }^{5,6}$. Moreover, because of hospital safety measures, the only human contact that the COVID-19 patient can experience is the one with the medical staff, all covered in special suits and face mask, which makes verbal and non-verbal communication hard especially for older people, who may 
suffer from hearing problems and cognitive impairment, increasing their feeling of isolation ${ }^{7}$. Overall, geriatric patients seem to be particularly vulnerable to the current COVID-19 pandemic from both a physical and psychological point of view.

The purpose of the present article is to explore and address COVID-19 experiences among older hospitalized people, describing and discussing their different psychological reactions. Moreover, insights about the role of the clinical psychologist during their hospital care path will be offered. Three prototypical clinical cases will be described for the purpose of the article. Those cases represent an elaboration of different patients encountered by clinical psychologists in one of Milan's biggest hospitals, in northern Italy. They are all older adults (over 70 years old) who accepted the psychological support offered by the Clinical Psychology Unit of the hospital. Clinical interviews have been delivered in-person at the patients' bed using the required personal protective equipment. Identifying details have been altered and different stories have been combined to protect the patients' privacy, but the core elements of their stories and the main psychological features are preserved.

\section{CLINICAL CASES}

Patients who are dealing with COVID-19 diagnosis and its clinical course may have very different emotional and cognitive difficulties, which result in different attitudes during the hospitalization. According to the authors' recent clinical experiences, there are three main psychological patterns among hospitalized older patients, summarized through the description of the following clinical cases.

\section{Frustration for the PResent - Renato}

\section{Biographical information and medical condition}

Renato is a 75 old patient who has been hospitalized for 4 weeks. He initially came to the hospital because of a nephrectomy. Then he contracted the COVID-19 virus and developed pneumonia. At the current moment, he is in stable mild medical conditions. He should be assuming a lot of liquids because of his nephrological condition, but he is not drinking enough. Because of his low treatment compliance, he may need to attend extra dialysis on his clinical routine.

\section{Psychological reaction to his condition}

During his recovery in the hospital, he has mostly shown anger feelings. The main reasons behind his anger are his current isolation from his loved ones, the physical restriction to his room and the impossibility of making decisions for himself. In other words, like many other COVID-19 patients, Renato is suffering because he shifted from an active life to hospitalization and isolation. In fact, Renato used to be a quite active and fit person before the hospitalization: he often would go hiking in the mountains, he would take long walks in the city, and he fancied travelling by camper with his wife. All these activities testify his constant desire and pursuit of freedom which now is off-limits because of COVID-19.

He expresses his current anger through rejection of medical staff and medical treatment: he is very edgy with the clinicians and he often complains especially about food and liquids assumption.

Beside anger, he shows grief for multiple recent losses: in different moments during his hospitalization, he received the news of the death of fifteen friends because of COVID-19. Those friends were approximately his age. Renato describes to the psychologist a big void left by the departure of those friends. He feels like his survival is not fair.

Also, the patient is sorry for his son who is dealing with both parents hospitalized at the same time: Renato's wife is currently hospitalized in a different facility, but she is in a fast recovery.

His only joyful thought is the fantasy of another hike in the mountain with his wife as soon as possible.

\section{Regrets for the past - Carlo}

\section{Biographical information and medical condition}

Carlo is 73 years old and he has been hospitalized for 4 weeks. His medical conditions are mild, he is in recovery. Nevertheless, he complains to doctors about treatments' side effects and minor urological problems as they were unbearable. This makes his discharge into a lower intensity care facility difficult.

\section{Psychological reaction to his condition}

Carlo's reaction to the current situation is characterized mostly by depression feelings: fear, guilt and shame.

First, he is very scared by the uncertainty and unpredictability of his clinical progression, even if he does not directly address the possibility of his own death.

Secondly, he feels a sense of guilt towards his wife, who is also affected by COVID-19 and currently hospitalized in the intensive care unit with very low chances of survival. He has not heard from her since she was intubated weeks ago. Before her intubation, she was writing him texts of encouragement and positivity. He regrets not showing his wife enough affection and attentions when he could. He describes her as the positive one of their couple: to his eyes, she has always been the optimist, strong, active one and the pillar of their family, while he 
sees himself as the fragile one. He feels like he is not worthy of surviving his wife.

He feels inadequate and guilty especially when he stops thinking about her critical conditions to complain about himself. His shame seems to reinforce his sadness in an endless vicious circle. As many other COVID-19 patients, Carlo is dealing with a mourning process which seems to catalyze almost all his mental space and energy.

His only positive thought is that his sons are coping well with the situation. He is proud of how strong they are proving to be.

\section{Toward acceptance of the future - Maria}

\section{Biographical information and medical condition}

Maria is an 87 years old patient who has been hospitalized for COVID-19 for 3 weeks. Her medical conditions were critical but now she shows slight improvements.

\section{Psychological reaction to his condition}

Maria seems peaceful and acceptant towards her situations and her medical conditions.

At first, she was afraid of a hypothetical recovery. She feared losing independence and becoming unable to take care of her husband, who is affected by Alzheimer's disease, currently at home with her son's family. She does not want to add another "burdens" to her son and her daughter in law. She stated that she would prefer dying instead. When slight improvements appeared in her clinical conditions she still talked about how it was acceptable for her to die, but she also started showing hope, will to fight, and sadness for the possibility of dying not surrounded by her loved ones.

Maria is satisfied with her life and her family and explains that if that was the end of it, she did not have many regrets. Talking about death with the psychologist, she once said: "I am not afraid, just a bit sorry to go".

During the sessions with the psychologist, Maria spends most of the time giving autobiographical narratives (maybe also because she is almost deaf so she cannot hear very much). She likes to tell stories about her life achievements and her skills, such as her work carrier and her family history.

Maria has been recently reflecting about faith and religion. She explained to the psychologist that she had never been a strong believer, but a few days earlier she had a dream at night in which Christ's face with a thorns crown appeared. The patient stated that this experience gave her a lot of peace and made her think about her death from a more positive perspective. Since the dream, she feels what she describes as an authentic faith.

\section{DISCUSSION}

The clinical cases' descriptions are not exhaustive, but they reflect and summarize the intense clinical experience that hospital psychologists have been collecting among older patients during the current COVID-19 outbreak. These three clinical cases allow us to draw some general conclusions that may be useful in the clinical care of other COVID-19 geriatric patients and their emotional needs.

Hospital psychologists noticed that older patients with COVID-19 are mostly aligned with the Kubler-Ross 5 stages model of grief ${ }^{8}$ : they seem to pass through denial, anger, bargaining, depression and acceptance. Renato is dealing with the anger phase, Carlo with the depression one and Maria seems to be in the last stage: acceptance. At the same time, as Kubler-Ross points out, there are moments when those patients are experiencing more than one phase at a time, shifting back and forth between stages: for example, Maria faces also some depression, even if is she mostly feels acceptance. Moreover, as Kubler-Ross stated in her model, Maria's acceptance is not to be confused with a wish to die, or the total loss of hope, instead it is a peaceful and calm perspective towards the possibility of death.

The phase of grief seems not to be determined by neither the stage of the disease nor the length of the hospitalization: Maria, who has been hospitalized for 3 weeks, shows a more advanced adjustment than Carlo, who has been hospitalized for 4 weeks and who is in better physical conditions then her. Personal characteristics and background probably influence the psychological reaction to the disease more than the clinical factors.

Kubler-Ross's model is mainly applied to the dying patients but neither Renato nor Carlo or Maria are dying. The COVID-19 progression is fast and unpredictable: patients may recover, despite their age. As a matter of fact, there have been different cases of COVID-19 survivals among people older than 90 years old ${ }^{9}$. In the presented cases there has not been a clear communication about the possibility of dying as long as information about the prognosis of the disease are still scarce and clinicians are not fully able to predict the disease course yet. Therefore, COVID-19 patients are less sure about their future life span compared to other patients who are described by Kubler-Ross' model. At the same time, older COVID-19 patients are aware that death is nor a rare case. In fact, due to the current pandemic, in northern Italy, the death rate is high, especially among older people ${ }^{10}$. Older hospitalized patients are likely to know some COVID-19 victims: it can be the death of multiple friends, such as Renato's, or the imminent 
death of a relative, such as Carlo's. Other patients experience the death of their hospital roommates. Those deaths remind patients of the possibility of their own death, which is strongly present in their minds even if the topic has not been addressed by healthcare professionals.

This is a unique situation: COVID-19 patients are dealing simultaneously with multiple mourning processes and the possibility of their own death, all because of the same illness and in a condition of almost total isolation imposed by safety measures, such as social distancing and quarantine. The high number of victims may lead to complex emotional processes characterized by negative feelings, such as guilt and shame. The former is felt by both Renato and Carlo for outliving their beloved, and the latter emerges in Carlo's case, where the inner question may be: "what right do I have to complain about my situation if my wife (companion, sister, daughter...) is dying?". Moreover, grief is complicated by a deep sense of loneliness enhanced by safety measures: people are living and eventually dying away from their family and friends and, in case of death, not even the celebration of their life through funerals is allowed. The fear of dying without her loved ones is present event in Maria's case, even though she mostly shows acceptance toward the possibility of her own death.

Nevertheless, hospital psychologists observed that COVID-19 patients usually not directly address their own death. A cultural factor must be considered: we live in a death-defying (or even denying) society and death is perceived as a failure in medicine ${ }^{11}$. The current pandemic is crushing this unrealistic but common belief, reminding us that medicine has limitations; that human beings are fragile, especially those who detain an old body; and that nature will soon or later make us more limited and then lead to death. Even the idea of recovery and rehabilitation among older patients can be accompanied by the fear of not going entirely back to the "old self", losing some degree of wellness and independence, as in Maria's case. This inevitable path can make us feel angry and frustrated, especially if we are used to an active and carefree lifestyle, like Renato. The avoidance of personal death's references may also be the result of a defense mechanism ${ }^{12}$ to protect themselves from an uncertain and threatening situation. Another reason behind this avoidance may be the lack of psychological space: the patients' mind is overloaded with the present moment. It is difficult for them to think about anything else than their current traumatic condition. In fact, everything in the hospital is focused on COVID-19: during hospitalization, patients have no distractions as they are frequently without common supplies as television and newspapers and the only human contact they experience is the one with the medical staff. Only when the patient's conditions improve, usually after some time, it becomes possible to think about the future, or to reflect upon the past. At the same time, they become able to address more transcendental topics, such as death and spirituality. Furthermore, as in Maria's case, the stability of the medical conditions, the exploration of the possibility of death, and spirituality seem to reinforce one another.

According to the hospital psychologists' experience, another aspect that has a key role in Maria's peaceful attitude towards death is the life-tales telling. Her biographical narrations seem to seal her existence in a positive way, allowing her to address the eventuality of her death peacefully. Biographical narrations are an effective way to process emotions and to overcome traumatic events ${ }^{13}$ but patients' storytelling needs a good listener. Usually, this role is picked up by relatives, but in the current pandemic, this is not possible. Medical staff is the main human contact that these patients are experiencing during hospitalization, but clinicians and nurses, already overworked, might feel overwhelmed to receive many personal stories and might not feel comfortable in being the only one attending this relational responsibility.

From the authors' recent clinical experience, psychologists can effectively assume the role of active listeners of the older COVID-19 patients' life stories and their existential thoughts, addressing both the patients' relational needs and, at the same time, partially relieving the medical staff from this burden. Collection of biographical narrations and support in the process of disease acceptance are pivotal tasks that hospital psychologists can offer in the older COVID-19 patient care management.

\section{References}

1 World Health Organization. Coronavirus disease 2019 (COVID-19): situation report, 108. World Health Organization, 2020 (https://www.who.int/docs/default-source/ coronaviruse/situation-reports/20200507covid-19-sitrep-108.pdf?sfvrsn=44cc8ed8_2).

2 D'Adamo H, Yoshikawa T, Ouslander JG. Coronavirus disease 2019 in geriatrics and long-term care: the ABCDs of COVID-19. J Am Geriatr Soc 2020;00:1-6. https://doi. org/10.1111/jgs.16445

3 Carvalho PM de M, Moreira MM, de Oliveira MNA, et al. The psychiatric impact of the novel coronavirus outbreak. Psychiatry Res 2020;286:112902. https://doi.org/10.1016/j. psychres.2020.112902

4 Bo H-X, Li W, Yang Y, et al. Posttraumatic stress symptoms and attitude toward crisis mental health services among clinically stable patients with COVID-19 in China. Psychol Med 2020;1-2. https://doi.org/10.1017/ S0033291720000999 
5 Chen N, Zhou M, Dong X, et al. Epidemiological and clinical characteristics of 99 cases of 2019 novel coronavirus pneumonia in Wuhan, China: a descriptive study. Lancet 2020;395:507-13. https://doi.org/10.1016/S01406736(20)30211-7

6 Shahid Z, Kalayanamitra R, McClafferty B, et al. COVID-19 and older adults: what we know. J Am Geriatr Soc 2020;00:1-4. https://doi.org/10.1111/jgs.16472

7 Schlögl M, Jones CA. Maintaining our humanity through the mask: mindful communication during COVID-19. J Am Geriatr Soc 2020;00:1-2. https://doi.org/10.1111/ jgs. 16488

8 Kubler-Ross E. On death and dying. New York: The Macmillan Company 1969.

9 Huang Y-M, Hong X-Z, Shen J, et al. China's oldest coronavirus survivors. J Am Geriatr Soc 2020:1-2. https:// doi.org/10.1111/jgs.16462

10 Onder G, Rezza G, Brusaferro S. Case-fatality rate and characteristics of patients dying in relation to COVID-19 in Italy. JAMA 2020. https://doi.org/10.1001/jama.2020.4683

11 Tucker T. Culture of death denial: relevant or rhetoric in medical education? J Palliat Med 2009;12:1105-8. https:// doi.org/10.1089/jpm.2009.0234

12 Silberfarb PM, Greer S. Psychological concomitants of cancer: clinical aspects. Am J Psychother 1982;36:470-8. https://doi.org/10.1176/appi.psychotherapy.1982.36.4.470

13 Pennebaker JW, Seagal JD. Forming a story: the health benefits of narrative. $J$ Clin Psychol 1999;55:1243-54. https://doi.org/10.1002/(SICl)10974679(199910)55:10<1243::AID-JCLP6>3.0.CO;2-N 